\title{
A step towards a single pill for cardiovascular disease prevention
}

A combination pill (Polypill) that contains blood-pressure-lowering drugs at low doses, plus a statin, aspirin and folic acid could drastically reduce cardiovascular disease if taken by individuals $\geq 55$ years, irrespective of their risk factors or history of cardiovascular disease, according to theoretical projections. The Indian Polycap Study by Yusuf and co-investigators was a phase II, double blind, randomized trial of one such Polypill: Polycap (Quintapill ${ }^{\circledR}$, Cadila Pharmaceuticals India, India). The researchers aimed to examine the effect of Polycap on blood pressure, lipids, heart rate and urinary thromboxane $\mathrm{B}_{2}$ and to determine whether the effects of Polycap were noninferior to those of its equivalent components.

The trial, conducted in India, included 2,053 individuals without cardiovascular disease, aged between 45 and 80 years, who had one cardiovascular risk factor. Participants were randomly allocated to receive Polycap $(n=412)$-three agents to lower blood pressure, a statin and aspirin-or to eight other groups (each of $\sim 200$ individuals) that received only certain components of Polycap. Study drugs were taken for 12 weeks.

\section{Projected reductions in} cardiovascular disease events with Polycap were $50-60 \% 77$

Polycap was noninferior to its individual components for blood-pressure lowering and heart-rate reduction. For example, blood pressure was reduced to a similar extent in the Polycap group and the group assigned to the three bloodpressure-lowering agents, with or without aspirin. However, reductions in LDL cholesterol with Polycap were less than those with the statin given alone, and reductions in urinary thromboxane $B_{2}$, although not significantly different with Polycap or aspirin alone, did not meet the prespecified noninferiority standard. Encouragingly, tolerability of Polycap did not seem to be worse than that of its active component drugs.

The results highlight that the effects of a Polypill cannot be assumed to be equivalent to the effects of its individual components taken separately. Projected reductions in cardiovascular disease events with Polycap were 50-60\%, less than previous estimated effects of a Polypill, but, nevertheless, substantial. Further trials will be needed to reveal if a Polypill strategy is safe and effective long-term.

\section{Carol Wilson}

Original article Indian Polycap Study (TIPS) et al. Effects of a polypill (Polycap) on risk factors in middle-aged individuals without cardiovascular disease (TIPS): a phase II, double-blind, randomised trial. Lancet 373 , 1341-1351 (2009). 